\title{
Designing Portable-repetitive Upper Extremity Arm Trainer for Post-stroke Patients Using Nigel Cross's Rational Method
}

\author{
A. S. Mariawati ${ }^{1, *}$, N. Wahyuni ${ }^{1}$, M. Fawaid $^{2}$, A. Umyati ${ }^{1}$, M. W. Riesha ${ }^{1}$, H. Iridistadi ${ }^{3}$ Henny $^{4}$ \\ ${ }^{1}$ Department of Industrial Engineering, University of Sultan Ageng Tirtayasa, Cilegon, Indonesia \\ ${ }^{2}$ Department of Mechanical Engineering Edu, University of Sultan Ageng Tirtayasa, Cilegon, Indonesia \\ ${ }^{3}$ Department of Industrial Engineering, Bandung Institute of Technology, Bandung, Indonesia \\ ${ }^{4}$ Department of Industrial Engineering, Indonesian Computer University, Bandung, Indonesia
}

Copyright $\odot 2019$ by authors, all rights reserved. Authors agree that this article remains permanently open access under the terms of the Creative Commons Attribution License 4.0 International License

\begin{abstract}
The common problems faced by post-stroke patients are the lack of facility and time for exercise in rehabilitation. This research aims to design upper extremity exercise portable equipment. The basic theory of this product's design is the Active Range of Motion. The design of upper extremity exercise portable equipment (P-RAT) uses Nigel Cross's Rational Method. As the result of the design, we obtained the best alternative solution for upper extremity exercise portable equipment with $43 \mathrm{~cm}$ of length, $8.5 \mathrm{~cm}$ of width and $11 \mathrm{~cm}$ of height equipped with rail extensions for $10 \mathrm{~cm}, 20 \mathrm{~cm}$, and $30 \mathrm{~cm}$ extra length, as well as the capability of elevation setting of the rails at $0^{\circ}$, $10^{\circ}, 20^{\circ}$, and $30^{\circ}$.
\end{abstract}

Keywords Range of Motion, Rehabilitation, Upper Extremity Arm Trainer

\section{Introduction}

Stroke or commonly called as a "cerebrovascular accident", is a symptom of neurological disorders resulting from cerebrovascular disease. Stroke is the most destructive brain disease with severe consequences, including psychological burden, physical, and financial for patients, families, and communities, according to [1].

Based on the results of [2], the prevalence of stroke in Indonesia was found to be 8.3 per 1,000 people, and those who have been diagnosed by health personnel are 6 per 1,000 inhabitants. Moreover, according to [3], an estimated 500,000 people have a stroke annually, approximately $2.5 \%$ or 125,000 people died, and the remaining minor defects happen almost every day, or an average of at least 3 days there was a resident of Indonesia, both young and old, died of a stroke.
Disability experienced by post-stroke victims will results in immobility and dependence. If this is allowed, it will result in behavioral changes that extend the healing or restoration of health, cause physical and psychological disorders as well as complications of other diseases, which will decrease the life quality of stroke survivors so that they cannot work and earn money, according to [3].

The upper limb dysfunction experienced by stroke victims is the most common functional disorder that occurs, as many as $88 \%$ of patients with stroke, according to research conducted by [4]. Post-stroke hemiparesis is one cause of stroke patients who experience a disability. The degree of disability experienced by stroke patients depends on the severity of hemiparesis experienced by patients. According [5], 30-60\% of patients who have hemiparesis will experience the loss of full hand function within 6 months post-stroke.

Loss of the ability to control the body's daily needs, such as the control of the lower body, i.e. from thigh to toe toes to move, then the control of body from the middle to the top of the shoulder to the fingers of the hand to grasp a spoon when eating, to lose the ability to speak and / or see are the effects that are felt by people with post-stroke. One avenue taken as an attempt to restore the system function of post-stroke patient's body is with rehabilitation.

Medical rehabilitation is an attempt to restore the patient's physical ability to the original state in the shortest time. Range of Motion (ROM) is one form of exercise in the process of rehabilitation which is still considered effective enough to prevent the occurrence of disability in patients with stroke. The results of research by Astrid (2008) found that increased muscle strength and functional ability improved significantly after being given a workout. This means ROM exercises influence on the increase in muscle strength and functional abilities of stroke patients with hemiparesis. 
Recovery of muscle strength is effective for patients with post-stroke hemiparesis, and it can be achieved by doing upper extremity exercises routinely and regularly. However, problems such as lack of facilities and trainers who can guide these exercises cause some kind of poststroke patients in hospitals, rehabilitation centers and at home do not get enough opportunities to do so. So we need a solution to overcome these problems so that the process of post-stroke patients' recovery could be optimal. According to [6], anthropometry is derived from the word "anthro" which means "man" and "metri" which means "measure", then by definition mean anthropometric science with respect to the measurement of the dimensions of the human body. Anthropometric will be used as ergonomic considerations in human interaction, so that the results of anthropometric data processing will determine a product dimension and shape of the product to be used by humans. This is in accordance with the principle of "the principle of user-centered design", because of the size and dimensions of a product design, physical environment, and the work area is derived from the size and dimensions of the human body.

The aim of this study is to design upper extremity exercise portable equipment, along with instructions on how to use the tool. Rational method Nigel Cross is used as a step to design tools and determining the dimensions and the right size for users is enhanced with anthropometric science. The tool will be used as a medium for post-stroke patients to recover their upper limb motor functions by doing exercise, wherever and whenever they need it.

\section{Methodology}

This research was conducted in the Medical Rehabilitation Installation of RSUP Dr. Wahidin Sudirohusodo Makassar, South Sulawesi. The research begins with direct observation of the state and activity of post-stroke victims with upper limbs hemiparesis during the rehabilitation process. Subsequently, researcher conducted initial questionnaires and interviews to 25 respondents i.e. doctors, nurses, and therapists to determine the outline of the shape of the rehabilitation process that is right and ideal for post-stroke patients with hemiparesis. Then it proceeds with the deployment of advanced questionnaire to the same respondents with an additional 33 respondents, from companion or the patient's family, to determine the level of interest and the main needs and expectations of potential users for the tool to be designed.

Once all the data is collected, and then it is processed by using the steps of Nigel Cross' rational method. Here are the steps:

1) Purposes Clarification/Identification of User Needs: The first phase of the design process, by the description of all the expectations and needs of the prospective users of the tool will be designed.

2) Determination of Function: The second stage of the design process, carried out by identifying the functions and sub-functions of the tool design process.

3) Develop of Requirements: The third stage of the design process, by making the specification criteria of a design solution that is needed.

4) Determination of Characteristics: The fourth stage of the design process, through Determination of targets to be achieved by the technical characteristics of tools designed, so that it can meet the needs of users.

5) Determination of Alternatives: The fifth stage of the design process, done by setting some combination of alternative concepts design tools to find a design solution that is fit for purpose design tools.

6) Evaluation of Alternatives: The sixth stage of the design process, by choosing a combination of the best concept of alternatives predetermined

7) Detailed Improvements: The last stage of the design process, with the aim to develop while keeping the value of the tool that is designed to include anthropometry factor in determining the dimensions and specifications of tools designed.

\section{Results}

\subsection{Purposes Clarification/Identification of User Needs}

Based on the results of weighing the value of the level of interest, we get a percentage of the value of user needs that are then ranked from the largest value to the smallest to determine priority needs based on their level of importance. They are as follows:

Table 1. Relative importance order

\begin{tabular}{lll}
\hline No & Level of Importance & Percentage (\%) \\
\hline 1 & Comfortable to use & 8,923 \\
\hline 2 & Safe to use & 8,801 \\
\hline 3 & Easy to use & 8,555 \\
\hline 4 & Easy to prepare & 8,514 \\
\hline 5 & Manual (w/o electricity or generator) & 8,473 \\
\hline 6 & Difficulty level setting (adjustable) & 8,309 \\
\hline 7 & Durable & 8,309 \\
\hline 8 & Practical (low space needed to storage) & 8,228 \\
\hline 9 & Portable & 8,105 \\
\hline 10 & Attractive design & 8,105 \\
\hline 11 & Robust design & 7,941 \\
\hline 12 & Easy to maintenance & 7,736 \\
\hline
\end{tabular}

From Table 1 above, we obtained information that the 
convenience factor, security, and ease of use, should be a top priority in the design. Because these factors are the desire or hope of major potential users, the tool that exercises the upper limbs of the body is designed. By ensuring the comfort, safety and ease of use, users will be interested in using the tool, because the main purpose of designing this tool will only be achieved if users can use it as often as possible, and to ensure these factors are implemented in the design, then the focus of this tool is expected to be achieved.

\subsection{Determination of Function}

General function of upper limb training tool is illustrated in the diagram of black box below.

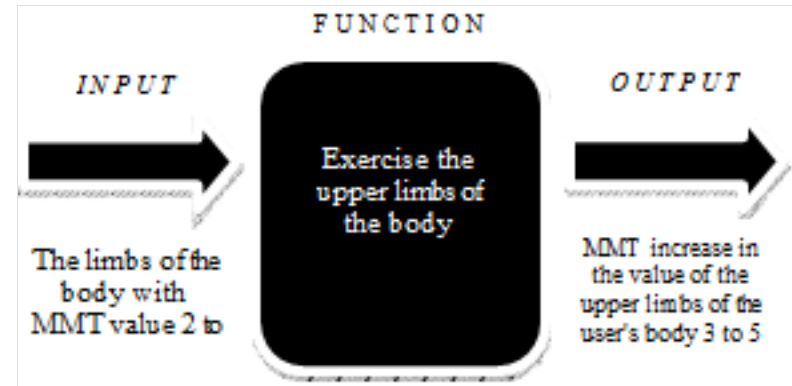

Figure 1. Black Box Diagram

Detailed function of this tool can be seen in the white box/transparent box diagram below.

\subsection{Develop of Requirements}

This stage aims to make an accurate specification criterion of a design solution, training tools necessary upper limbs.

Table 2. Criteria for comfort and security

\begin{tabular}{|c|c|}
\hline Purposes & Criteria \\
\hline \multirow[t]{9}{*}{ Comfort } & Hand grip comfortable grip: \\
\hline & - hand grip comfortable grip \\
\hline & - The design of the hand grip is based on the size of the anthropometric \\
\hline & - The surface of the hand grip is not rude \\
\hline & - $\quad$ Hand grip material coated rubber or foam \\
\hline & Rail's design: \\
\hline & - The length of the rail can be set \\
\hline & - $\quad$ Rail does not hinder the movement of hand grip \\
\hline & - $\quad$ Surface rail lubricated \\
\hline \multirow[t]{10}{*}{ Security } & No Harm: \\
\hline & - $\quad$ Safe to use \\
\hline & - Do not injurethe hand \\
\hline & - $\quad$ security between the rail and the box \\
\hline & - There is a barrier made of rubber \\
\hline & - $\quad$ No dangerous when stored \\
\hline & - $\quad$ Safe when united \\
\hline & - $\quad$ Equipped with safetylock \\
\hline & No Side Effect: \\
\hline & - Mechanism of action of the tool based on the method of therapy AROM \\
\hline
\end{tabular}


Table 3. Criteria for tool's design and durable

\begin{tabular}{|c|c|}
\hline Purposes & Criteria \\
\hline \multirow{30}{*}{$\begin{array}{l}\text { Tool's } \\
\text { design }\end{array}$} & Easy to prepared: \\
\hline & - $\quad$ SOP of Preparation \\
\hline & - $\quad$ Can be mounted on a bench or a wheelchair \\
\hline & - There is a backrest and a security lock slot \\
\hline & Easy to use: \\
\hline & - $\quad$ SOP of Use \\
\hline & - $\quad$ Double rail system \\
\hline & - Direction of movement back andforth \\
\hline & - Using two hands \\
\hline & Tool's system: \\
\hline & - $\quad$ Tool applying manual \\
\hline & - $\quad$ Operation using a poweruser \\
\hline & - $\quad$ Mechanism frequentative tool with repetition (repetitive) \\
\hline & - $\quad$ Mechanisms motor stimulation tool with two hands (bilateral) \\
\hline & Adjustable: \\
\hline & - $\quad$ The rails can be raised / lowered \\
\hline & - $\quad$ Tilt adjusting roller \\
\hline & - The degree of slope rail corresponding therapeutic methods AROM \\
\hline & Practical (easily stored): \\
\hline & - $\quad$ Minimize storage space \\
\hline & - $\quad$ Rail inserted into the box \\
\hline & - $\quad$ Box can be unified \\
\hline & - $\quad$ Portable \\
\hline & - Tool is lightweight \\
\hline & - $\quad$ Mass tool less than $5 \mathrm{~kg}$ \\
\hline & Display (visual appearance): \\
\hline & - $\quad$ Attractive design \\
\hline & - $\quad$ Minimalist design \\
\hline & - $\quad$ Capsule-shaped design \\
\hline & - $\quad$ Sturdy design \\
\hline \multirow[t]{9}{*}{ Durable } & Easy maintenance: \\
\hline & - $\quad$ Easy to clean \\
\hline & - $\quad$ Easy to beoverhauled \\
\hline & - $\quad$ SOP of Maintenance \\
\hline & Material of tools: \\
\hline & - The casing is made of plastic \\
\hline & - $\quad$ Frame is made of wood and aluminum \\
\hline & - The rails are made of aluminum \\
\hline & Hand grip made of wood \\
\hline
\end{tabular}

\subsection{Determination of Characteristics}

Through the description of the requirements that has been done before, we obtained the objectives and criteria for the user's needs. Thus, from these criteria we will get the results of the technical characteristics which aim to facilitate the process of resolving problems. After the technical characteristic shape had been obtained, data was processed through the matrix Quality Function Deployment (QFD). With a total weight obtained from QDF matrix that is equal to 1740 , so that the interests of the absolute value of the technical characteristics of upper limb training tool body is as follows: 
Table 4. Criteria for tool's design and durabal

\begin{tabular}{lll}
\hline No. & Technical characteristics & NKA \\
\hline 1 & Standardization system & 16,3 \\
\hline 2 & Determination materials & 14,2 \\
\hline 3 & The draft order & 13,3 \\
\hline 4 & Mechanism of the tool & 11,7 \\
\hline 5 & The design of the case & 10,6 \\
\hline 6 & Mechanisms of transformation tools & 9,31 \\
\hline 7 & Determination of complement components & 6,38 \\
\hline 8 & Anthropometric adjustment & 6,09 \\
\hline 9 & Using procedures & 4,66 \\
\hline 10 & Preparation procedures & 3,74 \\
\hline 11 & Maintenance procedures & 3,68 \\
\hline
\end{tabular}

\subsection{Determination of Alternatives}

Here are the results of an alternative grouping which has been determined based on a combination of concepts morphological attributes contained in the chart:

\section{Alternative I:}

1. Therapy based Active Range of Motion

2. Frame material using aluminum

3. Casing material using aluminum

4. Portable

5. The rail design uses two rail systems

6. Rails material using aluminum

7. Manual mechanism

8. Design hand grip using the I-bar grip

9. Hand grip material using aluminum

10. Hand grip coating using rubber

11. Box-shaped design

12. Using key-type clamp

13. Design of pedestal foot using rectangular box

14. Pedestal foot material using rubber

Alternative II:

1. Therapy-based Passive Range of Motion

2. Frame material using wood

3. Casing material using plastic

4. Semi-portable

5. The rail design uses two rail systems

6. Rails material using stainless steel

7. Automatic mechanism

8. Design hand grip using the T-bar grip

9. Hand grip material using plastic

10. Hand grip coating using foam

11. Capsule-shaped design

12. Using key-type clamp

13. Design of pedestal foot using rectangular box

14. Pedestal foot material using wood

Alternative III:

1. Therapy based Active Range of Motion

2. Frame material using wood

3. Casing material using plastic
4. Portable

5. The rail design uses two rail systems

6. Rails material using aluminum

7. Manual mechanism

8. Design hand grip using the T-bar grip

9. Hand grip material using plastic

10. Hand grip coating using rubber

11. Capsule-shaped design

12. Using key-type strap

13. Design of pedestal foot using $1 / 2$ sphere ball

14. Pedestal foot material using rubber

Alternative IV:

1. Therapy based Active Range of Motion

2. Frame material using steel

3. Casing material using wood

4. Portable

5. The rail design uses single rail systems

6. Rails material using steel

7. Manual mechanism

8. Design hand grip using the reverse L-bar grip

9. Hand grip material using wood

10. Hand grip coating using plastic

11. Sphere-shaped design

12. Using key-type strap

13. Design of pedestal foot using long rectangular box

14. Pedestal foot material using plastic

\subsection{Evaluation of Alternatives}

After determination of alternatives is carried out, concepts are selected to determine the most appropriate alternative combinations to accommodate the main purpose of design.

Based on the comparison of the alternatives, alternative concept with a total value of highest weight is the third alternative with a value of 367.13 . The upper limb training tool body will be designed based on the combination of the concepts contained in the third alternative.

\subsection{Detailed Improvement}

This stage is the last step of the design process of training tools upper limbs of the body by using a rational method. At the stage of detailed repair tool that exercises the upper limbs of the body will be designed using the results obtained from the previous steps to make use of ergonomic considerations.

After the determination and calculation of anthropometric data, the result for the recapitulation of data dimensions and measures used in the design of training tools on the body's limbs. The following is a recapitulation of the data and their dimensions and the percentile values each factor of allowances: 
Table 5. Anthropometric data summary

\begin{tabular}{ccccccc}
\hline Dim & Desc & Perc & - & Allowance & Measure & Purpose \\
\hline D23 & The length of the forearm & $50^{\text {th }}$ & $42.97 \mathrm{~cm}$ & $0.3 \mathrm{~cm}$ & $43 \mathrm{~cm}$ & Determination of box's length \\
\hline D36 & long first forward & & & & & \\
\hline D28 & Length of hand & $50^{\text {th }}$ & $5 \mathrm{~cm}$ & & & Determination of box's height \\
\hline D29 & Width of hand & $95^{\text {th }}$ & $9.87 \mathrm{~cm}$ & $3.31 \mathrm{~cm}$ & $13 \mathrm{~cm}$ & Determination of handgrip' s length \\
\hline
\end{tabular}

Here is a picture of a 3-D model of the design of training tools for the upper limbs of the body that are processed using software Autodesk AutoCAD 2012.

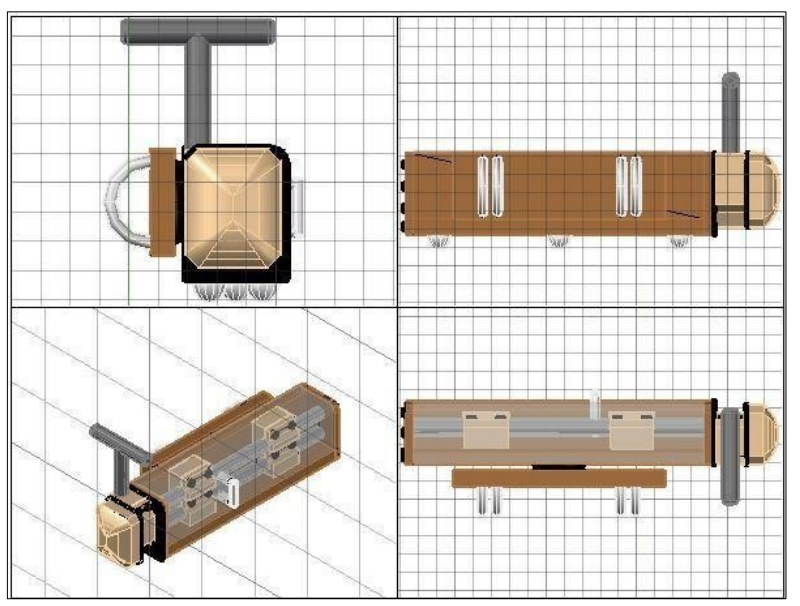

Figure 2. 3D Model Products

\section{Discussion}

Upper limb training tool body (P-RAT) designed based on the method of Active Range of Motion. Using Active Range of Motion serves as standardization of systems in this study because the exercise of Active Range of Motion can deliver significant results to increased muscle strength of the post-stroke patients. This is proven in several studies that have been conducted, among others by Astrid in 2008, which found that the results of increased muscle strength and functional ability improved significantly after being given a workout. This means ROM exercises influence on the increase in muscle strength and functional abilities of stroke patients with hemiparesis. In addition, Utomo research results in the same year also concluded the same thing, that the ROM exercises can improve muscle strength of thepatients.

The principle of the method Active Range of Motion or active range of motion, that is by letting the patient automated tools or motor. Light exercise such as ROM exercises have several advantages, among others, more easily learned and remembered by the patient, easy to implement and has a nursing intervention with a low cost that can be applied by stroke patients athome.

The working mechanism of upper limb training tools designed body that is simple, that is by utilizing the smooth that can move back and forth repeatedly. The initial step is to use these tools by placing and locking the wheelchair armrest, and then removes the lock to pull out the pipe rails of the box. Furthermore, the slope of the box is set, if necessary, by pulling out the box of the board hook up and play it back on the board and then locked hook. Tilting box causes the slope of the pipe rail or the use of tools, thus adding an additional burden of gravity when using the tool. This will stimulate arm muscles to contract so that blood flow will be smoother, which will have a positive effect on the body's limbs that were experiencing weakness.

Determination management of capabilities extension of the rail $10 \mathrm{~cm}, 20 \mathrm{~cm}$ and $30 \mathrm{~cm}$, and the angle of $0,10,20$, and 30 degrees, as the facility of training tools for upper limbs of the body that is designed and made based on consideration of the exercises active range of motion for members of the upper body motion. As is seen in Figure 4, the angle of the arm toward the shoulder to the third level of the active range of motion exercises are between 30-90 degrees. The arm posture will be experienced by the patient when exercising the upper limbs of the body with an angle of 10 degrees, and will continue to increase the degree of difficulty along with the addition of the angles being 20 to 30 degrees. While the determination of the extension of the rail, conducted by the global movement to exercise active external rotation range of motion. Currently, patients with post-stroke using the tool drills the upper limbs of the body with extension rails early $10 \mathrm{~cm}$ will form a posture corresponding second level with an angle below 0 degrees, and if the extension of the rail added $10 \mathrm{~cm}$, so that the total length of rail to $20 \mathrm{~cm}$, automatically posture will change as the third level with the angle of 0-20 degrees, so does the total length of rail $30 \mathrm{~cm}$.

Later, other advantages possessed by means of the upper limbs of the body (P-RAT) that are not owned by the predecessor product of the mechanisms and tools of different materials which led to P-RAT is more practical and lighter. The dominant predecessor product uses stainless steel material, so it has a total weight of $10.16 \mathrm{~kg}$ which leads to reduced mobility tool, while the P-RAT design uses wood materials, plastic, and aluminum, so it will be much lighter and portable than its predecessors. Besides, P-RAT has a system of mechanisms of transformation from / to the storage form (idle) from / to the form of use. In the form of storage, rail will be included in the second part of the tool box and put together using the strap hook interlocking board, so it will reduce the area of the tool. This will have an impact on the lack of space required to store the tool body workout upper limbs 
(P-RAT), when not in use.

\section{Conclusions}

Based on research that has been done on the design of training tools upper limbs of the body, it can be concluded, that the final draft of upper limb training tool body (P-RAT) has four main components, namely rail, hand grip, box, and hook board [7]. Tool length is $43 \mathrm{~cm}$, width $8.5 \mathrm{~cm}$, and height $11 \mathrm{~cm}$. Total extension rails that can be used is the maximum length of $30 \mathrm{~cm}$ so that the tool is $73 \mathrm{~cm}$. Tilt angle tool that can be used is $0^{\circ}, 10^{\circ}, 20^{\circ}$, and $30^{\circ}$. Then, the mechanism of the use of the tool is to put and locking tool with armrest on the wheelchair using the strap lock. Then release the locking rail to pull the rails out of the box, and adjust the tilt angle by turning roller tool that connects with the board lock box.

\section{REFERENCES}

[1] I. Junaidi, Panduan Praktis Pencegahan dan Pengobatan Stroke. Bhuana Ilmu Populer Kelompok Gramedia, 2004.

[2] T. Soendoro, On behalf of RISKESDAS team, Report on result of National Basic Health Research (RISKESDAS) 2007, The National Institute of Health Research and Develompment Ministry of Health Republic of Indonesi, Jakarta, 2008.

[3] Y. Cahyati, Perbandingan Latihan ROM Unilateral dan Latihan ROM Bilateral Terhadap Kekuatan Otot Pasien Hemiparese Akibat Stroke Iskemik di RSUD KotaTasikmalaya dan RSUD Kab. Ciamis, FIK UI, Depok, 2011.

[4] SI Zeferino, DM Aycock, Rehabilitation Nursing. Wiley Online Library, 2010.

[5] Kwakkel, et al, Probability of Regaining Dexterity in the Flaccid Upper Limb: Impact of Severity of Paresis and Time Since Onset in Acute Stroke, American Heart Association, Dallas, 2003.

[6] S. Wignjosoebroto, "Ergonomi Studi Gerak dan Waktu Teknik Analisis untuk Peningkatan Produktifitas Kerja”, Edisi Pertama, cetakan keempat, Surabaya, Indonesia, 2006.

[7] Jabarullah, N.H., Shabbir, M.S., Abbas, M., Siddiqi, A.F. \& Berti, S. (2019) Using random inquiry optimization method for provision of heat and cooling demand in hub systems for smart buildings, Sustainable Cities and Society, 47, 101475 